\title{
DESCRIPCIÓN DE LA HEMBRA DE CHEILOSIA ANDALUSIACA PEDERSEN, 1971 (DIPTERA, SYRPHIDAE) ${ }^{1}$
}

\author{
por \\ María Angeles Marcos-García ${ }^{2}$
}

\section{RESUMEN}

Se discribe la hembra Cheilosia andalusiaca Pedersen, 1971 y se amplia el conocimiento sobre la distribución geográfica de este endemismo ibérico. Así mismo, se incluye una clave de identificación de hembras de especies afines a $C h$. andalusiaca Pedersen conocidas en la actualidad en la Península Ibérica.

\section{SUMMARY}

The female of Cheilosia andalusiaca Pedersen, 1971 is described and the knowledge about the geographical distribution of this Iberian endemism is enlarged. A key of identification of females of the similar species to $\mathrm{Ch}$. andalusiaca Pedersen that are known in the actuality in the Iberian Peninsule, is also included.

\section{PALABRAS CLAVE}

Cheilosia andalusiaca, description, female, Diptera, Syrphidae.

\section{DESCRIPCIÓN DE LA HEMBRA}

Cheilosia andalusiaca Pedersen, 1971 Steenstrupia 1 (21), p. 235.

Ojos cubiertos por setas blanquecinas. Arista antenal oscura, con setas ligeramente más largas que en el macho. El tercer artejo antenal es de forma

(1) Trabajo realizado en el contexto del Proyecto de Investigación número PR84-0921-CO2-02, subvencionado por la C.A.I.C.Y.T.

(2) Departamento de Zoología, Facultad de Biología, Universidad de Salamanca, 37071SALAMANCA. 
redondeada, pardo rojizo aunque con su parte superior oscurecida o negruzca. La frente es brillante, con setas blanquecinas y recorrida longitudinalmente por dos surcos paralelos, uno a cada lado, cubiertos de pulverulencia grisácea. En su parte anterior, estos dos surcos se comunican mediante un tercero transverso, paralelo a la língula y carente de pruinosidad. La lúnula y este último surco transverso, están unidos por una pequeña depresión mediana sin puntuación. El vértex tiene setas pálidas. El perfil epistomático es de forma semejante al macho, poco excavado desde la base de las antenas hasta el tubérculo epistomático. El occipucio posee pruinosidad grisácea con setas amarillentas.

Mesonoto y escudete como en el macho, cubiertos por setas amarillentas más cortas que en el otro sexo y ligeramente tumbadas. Posee macroquetas rubias situadas en el borde posterior del escudete. Alas ligeramente oscurecidas, siendo su venación semejante a la del macho. Escámula blanco-amarillenta con su márgen amarillo. Halterios parduzcos con su tubérculo oscurecido. Patas completamente negras a excepción de la zona de articulación del fémur con la tibia que en los tres pares de patas presenta una coloración amarillenta.

Abdomen en todo semejante al del macho.

Longitud total: $9,5-10 \mathrm{~mm}$.

\section{MATERIAL ESTUDIADO}

Cáceres: Puerto del Torno, 950 m., 4-IV-81, 1 Ơ y 2 O९(*) (M. ${ }^{a}$ A. Marcos, leg.). San Martín de Trevejo, 900 m., 19-IV-81, 1 (M. ${ }^{a}$ A. Marcos, leg.).

León: Laguna de Arbás, Puerto de Leitariegos, 13-VI-86, $10^{\text {( }}$ (M. ${ }^{\mathrm{a}} \mathrm{A}$. Marcos, leg.).

Salamanca: El Calvitero, Sierra de Candelario, 2.300 m., 9-VI-82, 1 O (C. Urones, leg.). La Honfría, Linares de Riofrío, 21-IV-77, 1 Ơ $\left.^{*}\right)$ (M. ${ }^{\mathrm{a}}$ A. Marcos, leg.).

El material mencionado se encuentra depositado en la colección de la autora, actualmente depositada en el Departamento de Zoología de la Facultad de Biología de la Universidad de Salamanca, a excepción de una hembra y dos machos señalados con un $\left(^{*}\right)$ que fueron enviados en el año 1982 al doctor Pedersen para que, como autor de la descripción de $C h$. andalusiaca, emitiese su juicio.

\section{DISCUSIÓN}

Cheilosia andalusiaca Pedersen, 1971, fue descrita con tres machos procedentes de Río Lanjarón, localidad granadina situada en Sierra Nevada a 1.600 m. s. n. m., representando hasta el momento la serie tipo, los únicos ejemplares que se conocían de este endemismo ibérico. Con los datos anteriormente expuestos, se confirma después de más de 16 años, la existencia de esta especie y se amplía considerablemente su distribución geográfica en el ámbito peninsular ibérico hacia puntos más septentrionales ya que el macho de la provincia de León, fue capturado en una localidad situada en plena Cordillera Cantábrica.

El gran parecido morfológico que presentan estas hembras con la descripción original del macho en cuanto a silueta del perfil de la cabeza, coloración de las patas, halterios y setas del mesonoto, escudete y abdomen, así como el 
hecho de haber capturado un macho de esta especie junto a dos de las hembras descritas, me indujo a considerarlas como las hembras de $C h$. andalusiaca $\mathrm{Pe}-$ dersen.

Por otra parte, Pedersen en la descripción original del macho, remarca la ausencia de macroquetas en el borde posterior del escudete. No obstante, dicho escudete en ambos sexos se presenta además cubierto por largas setas de color amarillento que tal vez contribuyeron a que las macroquetas del borde escutelar, también de la misma coloración, pasaran inadvertidaas al autor de la especie.

Características morfológicas de la hembra no afines al macho, son la coloración de las setas oculares, negras en el macho y blanquecinas en la hembra, así como el color de las macroquetas mesotorácicas, la mayor parte amarillentas en la hembra y todas negras en el macho.

Quiero destacar que tanto los ejemplares sobre los que se basó la descripción original (procedentes de Sierra Nevada), como los aquí mencionados (capturados en sierras del Sistema Central y Cordillera Cantábrica), se encontraron volando en áreas montañosas de influencia atlántica situadas por encima de los 900 m. s. n. m.

Excede la treintena el número de especies del género Cheilosia Meigen, 1822 que hasta el momento se conocen como integrantes de la sirfidofauna ibérica (GIL-COLLADO, 1930; GOOT van der, 1958; GOOT van der y LUCAS, 1968; LECLERQ, 1963 y 1971; MARCOS-GARCİA, 1985, 1986 y en prensa; y PEDERSEN, 1971).

A continuación se expone una clave en la que se incluyen únicamente el conjunto de especies españolas cuyas hembras presentan ojos pubescentes, epistoma con setas sólo en los márgenes oculares y escudete portador de setas marginales, grupo al cual pertenece la hembra de $C h$. andalusiaca.

\section{CLAVE DE প९}

Caracteres del grupo: ojos pubescentes. Escudete con macroquetas en su borde posterior. Epistoma con setas sólo en los márgenes oculares (especies del grupo D de SACK, 1932).

1 Patas completamente negras o sólo con la zona de articulación del fémur con la tibia, de coloración más pálida ........................... 2

- Patas en gran parte rojizo-amarillentas................................ 3

2 Alas amarillentas en su base. Tubérculo epistomático redondeado y situado en el centro del epistoma. Arista antenal con cilios de longitud aproximada a la anchura en su parte basal. Tercer artejo antenal negro y cubierto de pulverulencia dorada: Ch. impressa Lw.

- Alas uniformemente oscurecidas en toda su extensión. Tubérculo epistomático desplazado hacia la parte inferior. Arista antenal con cilios de longitud inferior al grosor de la misma. Tercer artejo antenal negro, con coloración rojiza en su parte inferior más o menos extendida: Ch. audalusiaca Peder.

3 Mesonoto y escudete cubiertos por dos tipos de setas, unas largas y ne- 
gras y otras cortas y blanquecinas. Frente con dos surcos longitudinares, estrecha en el vértex y ensanchándose progresivamente hasta la boca: $C h$. gigantea (Zett.).

- Mesonoto y escudete cubiertos por setas de un solo tamaño o color 4

4 Tercer artejo antenal de coloración negruzca ....................... 5

- Tercer artejo antenal de coloración parduzca a rojizo-amarillenta .. 7

5 Mesonoto con gruesa puntuación y cubierto por setas de dos colores pero todas del mismo tamaño. Tercer artejo antenal de forma cuadrangular, con ángulos romos. Abdomen cubierto de largas setas de coloración grisácea: Ch. zetterstedti Beck.

- Mesonoto con fina puntuación ....................................... 6

6 Tercer artejo antenal más largo que ancho. Setas oculares cortas, escasas y de coloración grisácea. Tarsos medianos del primero y segundo par de patas de coloración rojiza. Abdomen de bordes casi paralelos: Ch. mutabilis Fall.

- Tercer artejo antenal tan largo como ancho. Setas oculares en su mayor parte oscuras. Los primeros tarsómeros del primero y segundo par de patas, más o menos rojizos. Abdomen ovalado: Ch. vernalis Fall.

7 Tarsos del tercer par de patas negros o pardo-negruzcos. Mesonoto y escudete con gruesa puntuación. Setas oculares blanquecinas: $C h$. correcta Beck.

- Tarsos del tercer par de patas de coloración amarillenta ............ 8

8 Abdomen estrecho y largo, especie de pequeño tamaño. Frente con dos surcos longitudinales. Setas oculares blanquecinas. Long. $6 \mathrm{~mm}$.: Ch. prae$\operatorname{cox}$ Zett.

- Abdomen ovalado, especie de mayor tamaño. Tercer artejo antenal pequeño y elíptico, con arista corta y glabra. Long. 8-10 mm.: Ch. fraterna (Meig.).

\section{AGRADECIMIENTO}

Quiero agradecer al doctor Van der Goot del Instituto de Taxonomía Zoológica de Amsterdam, al doctor T. R. Nielsen de Noruega y a C. Claussen de Alemania, sus amables comentarios al respecto tras el examen de parte del material de mi colección. 


\section{BIBLIOGRAFÍA}

GIL-COLLADO, J. (1930), Monografía de los sírfidos de España, Trab. Mus. Nac. Cienc. Nat., Serie Zool, 54, 378 pp.

GOOT V. S. van der (1958), Quelques Syrphides (Diptera) des Pyrénées et de la Sierra Nevada, Ent. Ber. XVIII: 93-96.

GOOT V. S. van der et J. A. LUCAS (1968), Recolección de Sírfidos en Albarracín, provincia de Teruel, durante el verano de 1965, Graellsia, XXIII (1967): 111-119.

LECLERQ, M. (1963), Syrphidae de España (Diptera). Graellsia XX: 125-129.

LECLERQ, M. (1971), Syrphidae (Diptera) des Pyrénées (Huesca, Lérida, Andorra, Gerona), Pirineos, 27 (102): 21-25.

MARCOS-GARCÍA, M. ${ }^{a}$ A. (1985), Contribución al conocimiento de la sirfidofauna del Pirineo del Alto Aragón, I (Diptera, Syrphidae), Bol. Soc. Port. Ent., 1 (1): 511-520.

MARCOS-GARCÍA, M. ${ }^{a}$ A. (1986), Los Syrphidae (Diptera) de las Sierras occidentales del Sistema Central español: Subfamilias Chrysotoxinae, Sphegininae, Chilosiinae, Pelecocerinae, Volucellinae y Cinxiinae, Bol. Asoc. esp. Ent., 10: 159-180.

MARCOS-GARCÍA, M. ${ }^{2}$ A. (en prensa). Sobre la presencia de Cheilosia paralobi Malski, 1962 y Cheilosia latifacies Loew, 1857 en la Península Ibérica (Diptera, Syrphidae), An. Biol. (Biología Animal).

PEDERSEN, E. T. (1971) Some Syrphidae from Spain, with descriptions of two new species (Insecta, Diptera), St. Zool. Mus. Univ. Copenhagen, 1: 229-245.

SACK, P. (1932), Die Fliegen der Palaearktischen Region, 31 Syrphidae, Stutt. Schweiz., 451 pp. 